\title{
Relaxing and stimulating effects of odors on time perception and their modulation by expectancy
}

\author{
Alessia Baccarani ${ }^{1}$ (D) Simon Grondin ${ }^{2} \cdot$ Vincent Laflamme $^{2} \cdot$ Renaud Brochard $^{1}$ \\ Accepted: 15 October 2020 / Published online: 6 November 2020 \\ (C) The Psychonomic Society, Inc. 2020
}

\begin{abstract}
Although several studies have reported relaxing and stimulating effects of odors on physiology and behavior, little is known about their underlying mechanisms. It has been proposed that participant expectancy could explain these activation effects. Since emotional stimuli are known to modulate time perception, here we used the temporal bisection task to determine whether odors have objective relaxing and stimulating effects by respectively slowing down or speeding up the internal clock and whether prior expectancy could alter these effects. In Experiment 1, 118 participants were presented either with a strawberry odor or an odorless blank. In Experiment 2, 132 participants were presented either with a lemon odor or an odorless blank. In both experiments, expectancy was manipulated using suggestion (verbal instructions). The stimulus was either described as relaxing or stimulating, or was not described. In the absence of prior suggestion, findings showed that, compared to participants presented with an odorless blank, participants presented with the strawberry odor underestimated sound durations (i.e., a relaxing effect) whereas participants presented with the lemon odor overestimated them (i.e., a stimulating effect). These results confirm that pleasant odors can have objective relaxing and stimulating effects by themselves, which are better explained by arousal-based mechanisms rather than attentional distraction. Furthermore, in both experiments, incongruent suggestions undid the effects of both odors without reversing them completely (i.e., strawberry did not become stimulating even if participants were told so). Both these bottom-up and top-down influences should be considered when investigating the emotional impact of odors on human behavior.
\end{abstract}

Keywords Odor · Time perception $\cdot$ Expectancy $\cdot$ Arousal $\cdot$ Emotion

\section{Introduction}

Supplementary Information The online version contains supplementary material available at https://doi.org/10.3758/s13414-02002182-0.

Alessia Baccarani

alessia.baccarani@u-bourgogne.fr

Simon Grondin

simon.grondin@psy.ulaval.ca

Vincent Laflamme

vincentlaflamme.vl@gmail.com

Renaud Brochard

renaud.brochard@u-bourgogne.fr

1 Centre des Sciences du Goût et de l'Alimentation (CSGA), AGROSUP-CNRS-INRAE-Université Bourgogne Franche-Comté, 9 E Boulevard Jeanne d'Arc, 21000 Dijon, France

2 Ecole de Psychologie, Université Laval, Pavillon Félix-Antoine-Savard Local 1142, Québec, Québec G1V 0A6, Canada
Over the course of history, odors have commonly been used by humans as powerful modulators of their emotional states. A growing number of studies has confirmed the emotional impact of odors, such as relaxing and stimulating effects on both physiology (Diego et al., 1998; Sayorwan et al., 2012; Sayowan, Siripornpanich, Hongratanaworakit, Kotchabhakdi, \& Ruangrungsi, 2013) and behavior (for reviews see Herz, 2009; Hongratanaworakit, 2004; Johnson, 2011). The activation properties of odors are now considered major features of olfactory-elicited emotions in addition to their relative (un)pleasantness, according to Russell's classic bidimensional model (i.e., arousal dimension; e.g., Bensafi et al., 2002). This is also reflected within more recent multidimensional approaches (Baccarani, Brand, Dacremont, Valentin, \& Brochard, 2020; Chrea et al., 2009; Delplanque et al., 2012; Ferdenzi et al., 2013; Lemercier-Talbot et al., 2019; Porcherot et al., 2010). However, the relaxing and stimulating effects of odors have been much less investigated than their hedonic 
valence and little is yet known about their underlying mechanisms (Herz, 2009). Investigating how emotional stimuli impact time processing has been particularly useful in understanding these mechanisms. Indeed, one of the most salient features of emotional external stimuli on individuals is their effect on perceived duration. This effect is specifically related to the arousal dimension, as demonstrated by the extensive literature where visual (Droit-Volet, Fayolle, \& Gil, 2011; Gagnon, Bégin, Laflamme, \& Grondin, 2018; Gil \& DroitVolet, 2011, 2012) or auditory stimuli (Droit-Volet, Ramos, Bueno, \& Bigand, 2013; Mioni, Laflamme, Grassi, \& Grondin, 2018; Noulhiane, Mella, Samson, Ragot, \& Pouthas, 2007; Voyer \& Reuangrith, 2015) were used. In this regard, very few studies have yet considered using odors (Schreuder, Hoeksma, Smeets, \& Semin, 2014; Yue, Gao, Chen, \& Wu, 2016). The purpose of the present study was to examine the mechanisms that underlie the potential distortion of time perception when relaxing and stimulating odors are used.

\section{Emotionally-induced time distortions and involved mechanisms}

Just like any information processed by the human brain, psychological time does not necessarily mirror the physical world, but is generally distorted according to the conditions in which a perceiver is placed (Grondin, 2010; Lake, LaBar, \& Meck, 2016). The effect on the perceived duration of emotionally evocative stimuli is now a well identified phenomenon (Droit-Volet, Fayolle, Lamotte, \& Gil, 2013; Droit-Volet \& Meck, 2007; Droit-Volet, Ramos, et al., 2013; Gamache, Grondin, \& Zakay, 2011; Grondin, Laflamme, Bienvenue, Labonté, \& Roy, 2015; Schirmer, 2016; Vallet, Laflamme, \& Grondin, 2019; for a review see Lake et al., 2016). Studies investigating the influence of valence and arousal on time perception typically use prospective paradigms (see Grondin, 2010, or Grondin, 2020, for a systematic presentation of the main methods used in time perception studies) in which participants are informed that they will have to estimate the duration of target intervals (Droit-Volet, Meck, \& Penney, 2007; Frederickx et al., 2013). These emotional effects on temporal processing are well explained by the pacemaker-accumulator internal clock model (Gibbon, Church, \& Meck, 1984; Treisman, 1963; for a recent review, see Lake et al., 2016). In this model, time is processed according to an internal clock composed of a pacemaker that emits pulses, a switch component that closes when a time judgment is required, and an accumulator of these pulses. It is the number of accumulated pulses that provides a basis for judging the duration of a given interval. This accumulation provides the length of the interval that needs to be timed, which is then compared to durations encoded in memory for decision making.
Previous studies investigated the impact of arousal on time perception with emotional stimuli (e.g., fear - Grommet et al., 2011; pictures of mutilation - Grondin, Laflamme, \& Gontier, 2014; or stress - Boltz, 1994), non-emotional stimuli (physical activity - Jakubowski et al., 2015; fatigue - Miró, Cano, Espinosa-Fernández, \& Buela-Casal, 2003 ; or click trains technique - Penton-Voak, Edwards, Percival, \& Wearden, 1996), or, recently, with both emotional and non-emotional stimuli (click trains and negative sounds - Williams, Solodow, Henderson, Stewart, \& Jones, 2020). A high level of arousal speeds up the rate at which the pacemaker emits pulses, leading to an overestimation of duration (Grommet et al., 2011; Wearden, Pilkington, \& Carter, 1999). With a lower arousal level, the pacemaker rate slows down and fewer pulses are accumulated, thus leading to an underestimation of duration.

Later adaptations of the model added an attentional-gate component (Gamache et al., 2011; Lejeune, 2000). This gate is responsible for the allocation of attentional resources to the temporal task. Thus, more pulses are accumulated when time is considered to be relevant, while fewer pulses are accumulated if attention is allocated elsewhere, to a non-temporal task. In other words, time "flies" when you don't pay attention to it. Thus, emotional stimuli can either affect the rate of the pacemaker of the internal clock (arousal-based mechanism) or the switch/gate opening process (attention-based mechanism).

\section{Olfactory-induced time distortions}

The effects of odors on time perception have been studied only very recently (Brand, Thiabaud, \& Dray, 2016; Gros et al., 2015; Millot, Laurent, \& Casini, 2016; Schreuder et al., 2014; Yue et al., 2016; Zhou, Feng, Chen, \& Zhou, 2018). In an experiment by Gros et al. (2015), participants had to estimate the duration of a sound (pure sounds, less than $2 \mathrm{~s})$ that was preceded by an emotional olfactory or visual stimulus with a positive or negative valence. Regardless of the odor presented, olfactory priming led participants to systematically overestimate short sound durations compared to prior sound estimations without odor. These results suggest that odors (regardless of their valence) have an arousing effect on the internal clock. However, the results were different in a study by Schreuder et al. (2014) in which rosemary and peppermint odors had distinct effects on a time production task. This study can be distinguished from the aforementioned studies because these authors selected odors according to their arousing (and not pleasantness) properties, with both odors considered to be pleasant but with rosemary considered to be stimulating and peppermint relaxing. These authors found that when participants were exposed to the rosemary odor, there was, compared to a control group, a significant overestimation of time. There was, however, no such effect with peppermint. Moreover, in this study, the author did not 
explain the overestimation of time induced by the rosemary odor by an arousal-based mechanism since they did not observe any modifications of the physiological arousal-related measures (i.e., skin conductance and heart rate). Gros et al. (2015) suggested that these contradictory findings might be due to the range of the durations used. This is in agreement with prior studies in the time literature that generally report distinct mechanisms for short and long durations in temporal bisection and temporal estimation tasks (Droit-Volet \& Gil, 2009; Droit-Volet \& Meck, 2007). In this respect, Millot et al. (2016) investigated the influence of odors on time perception, using a temporal bisection task with both short sub-second durations (centered around $400 \mathrm{~ms}$ ) and long supra-second durations (centered around 2,000 ms). These authors showed that an unpleasant odor (decanoic acid) led participants to underestimate short durations and to overestimate long durations. The former effect was interpreted as an automatic capture of attention whereas the latter was interpreted as an arousing effect of the odor. In a study by Yue et al. (2016), participants were exposed to one unpleasant arousing odor, garlic, and to two pleasant odors, jasmine and lavender, which are respectively considered to have high and low arousal properties. In a time reproduction task, participants produced longer time intervals when exposed to the lavender odor compared to real durations and other olfactory groups (i.e., jasmine and garlic). This effect was observed only for short-time sound durations (centered around 1,000 ms), but not for long-time ones (centered around 4,000 ms).

\section{Time distortions and the relaxing and stimulating effects of odors}

Because the vast majority of studies only manipulated the valence properties (pleasantness and unpleasantness) and not the activation properties of odors, the underlying mechanisms of olfactory-induced emotional effects on time perception remain an open question, especially in the case of pleasant odors. In the present study, odors that are considered relaxing or stimulating were presented during a temporal bisection task. The temporal bisection task is commonly employed within the field of time perception (Grondin, 2010; Kopec \& Brody, 2010) and emotions (e.g., Droit-Volet, Ramos, et al., 2013; Gagnon et al., 2018; Lake et al., 2016). It will allow us to distinguish whether the effects of odors are due to a state of arousal rather than a modification of attention. In a temporal bisection task, participants are first presented with a short and a long sound duration (anchors, i.e., standard durations). Then, in a test phase, they must categorize sound durations (anchors and intermediates) as being closer to either the short or long standard durations that they have previously learned. Two measures are taken from the psychometric function resulting from this task: the difference limen (DL), which is considered as participants' temporal sensitivity, and the bisection point, sometimes referred to as the point of subjective equality (PSE) (Grondin, 2008). The PSE allows us to determine whether participants present any change in their temporal perception that might lead to underestimating (i.e., rightward shift of the psychometric curve) or overestimating durations (i.e., leftward shift of the curve).

If odors automatically capture the attention, we should observe an underestimation of durations regardless of the odor presented. However, if odors modify the state of arousal, a relaxing odor (i.e., strawberry) should lead participants to underestimate durations, whereas a stimulating one (i.e., lemon) should result in an overestimation of durations. Sub-second sound durations were selected rather than supra-second ones in order to target involuntary processes.

\section{Expectancy effects: Towards a psychological mechanism}

Using an indirect measure such as a temporal bisection task also enabled us to implement the second main goal of the present studies, i.e., to implicitly evaluate the potential impact of the participant's expectancy toward the relaxing and stimulating effects of odors. Indeed, some studies have suggested that these effects might only be due to prior knowledge (Campenni, Crawley, \& Meier, 2004; Howard \& Hughes, 2008) rather than being genuinely emotional. The strong influence of top-down processes on human information processing is now well documented within many research domains, namely the placebo effect, the sensory perception of food and drink, etc. (Atlas \& Wager, 2013; Grabenhorst, Rolls, \& Bilderbeck, 2008; Piqueras-Fiszman \& Spence, 2015; Yeomans, Chambers, Blumenthal, \& Blake, 2008; Zellner, Strickhouser, \& Tornow, 2004), with some studies already implementing the olfactory modality (Dalton, 1996, 1999, 2000; Dalton, Wysocki, Brody, \& Lawley, 1997). However, only a few studies have specifically investigated the influence of expectancies in relation to the relaxing and stimulating properties of odors, and, when this is the case, only physiological measures were used. In a study by Campenni et al. (2004), participants' heart rate and skin conductance were recorded before and during exposure to ambient odors that are considered to be either relaxing (i.e., lavender) or stimulating (i.e., neroli). In an initial verbal message to the participant, the experimenters described the odors as being either relaxing or stimulating, or did not suggest anything. Findings showed no impact of a priori relaxing and stimulating odors on physiological indices. However, when compared to a condition containing no odor, the presentation of prior relaxing and stimulating suggestions had a significant influence on these indices, regardless of the odor presented. Similarly, Howard and Hughes (2008) reported no relaxing effect of lavender on the galvanic skin response after an 
arousing cognitive task but found a significant impact of instructional priming.

Thus, the purpose of the present studies was twofold: (1) to investigate if odors that are considered relaxing or stimulating would alter the rate of pulse emission in the internal clock's pacemaker and (2) to examine if prior verbal suggestions could modulate these putative effects in order to disentangle perceptual signal-driven influences from manipulated prior expectancies. In Experiment 1, we investigated whether participants who were presented with a strawberry odor, which is considered to be a relaxing odor according to a pretest and the literature (Martin, 1998; Porcherot et al., 2010), would slow down the rate of the pacemaker's pulse emission in their internal clock. This action on the internal clock would be reflected by a higher PSE when compared to an odorless blank condition. Moreover, we investigated whether prior suggestions describing this olfactory stimulus as being relaxing or stimulating would modulate this potential effect. In Experiment 2, we examined whether participants presented with a lemon odor, which is considered to be a stimulating odor according to a pretest and the literature (Diego et al., 1998; Guéguen \& Petr, 2006; Kiecolt-Glaser et al., 2008; Kikuchi, Yamaguchi, Tanida, Abe, \& Uenoyama, 1992) would rather increase the rate of the pacemaker's pulse emission. This effect would be reflected by a lower PSE when compared to an odorless blank condition. Moreover, as in Experiment 1, we tested whether this effect could be modulated by a prior description of the olfactory stimulus in terms of presupposed relaxing or stimulating properties.

\section{Experiment 1}

\section{Method}

\section{Participants}

One hundred and eighteen female students from Burgundy University $\left(M_{\text {age }}=18.77 \pm 1.71\right.$ years $)$ were distributed randomly into six independent groups in relation to olfactory condition (i.e., strawberry odor or odorless blank) and prior verbal suggestion about arousal (i.e., no-arousal suggestion, relaxing, stimulating): strawberry-no-arousal $(N=21)$, strawberry-relaxing $(N=19)$, strawberry-stimulating $(N=$ 18), blank-no-arousal $(N=21)$, blank-relaxing $(N=19)$, and blank-stimulating $(N=20)$ (see Table 1). The sample size was determined based on a previous study that examines the influence of relaxing and stimulating odors on time processing (Schreuder et al., 2014). Participants were first-year psychology students enrolled as part of an introductory tutorial class on methods in experimental psychology. All participants provided their consent prior to participation. The study was conducted in accordance with the Declaration of Helsinki. All
Table 1 Experiment 1: Mean of Point of Subjective Equality (PSE) and standard deviation (SD) according to Olfactory (i.e., Strawberry or Odorless Blank) and Suggestion (No-arousal, Relaxing, Stimulating) conditions

\begin{tabular}{lllllllll}
\hline & \multicolumn{3}{c}{ Strawberry odor } & & & \multicolumn{3}{c}{ Odorless blank } \\
\cline { 2 - 3 } \cline { 7 - 8 } & N & PSE mean & SD & & N & PSE mean & SD \\
\hline No-arousal & 21 & $396.01^{*}$ & 40.10 & & 21 & 370.42 & 30.03 \\
Relaxing & 19 & $395.72^{*}$ & 52.56 & & 19 & 390.43 & 35.25 \\
Stimulating & 18 & 367.69 & 40.14 & & 20 & $403.46^{*}$ & 41.32 \\
\hline
\end{tabular}

$* p<.05$ compared to odorless blank group in no-arousal suggestion condition

participants self-reported normal olfactory sensitivity. Participants who reported suffering from a head cold, nose congestion, or chronic allergies were excluded from the analysis.

\section{Stimuli}

Olfactory stimuli A strawberry odorant ("Le Meilleur du chef ${ }^{\text {TM" }}$ aroma), $4 \mathrm{~mL}$ of a 7.5.10 $0^{-3}$ solution, was loaded inside an empty sniffin' stick (Burghart ${ }^{\mathrm{TM}}$ ). This stimulus was selected as a relaxing odor because it was considered to be the most relaxing stimulus among a pre-selection of 18 odors in a pretest (for more details about the pretest, see Online Supplementary Material). Blank sniffin' sticks contained only an odorless solvent (distilled water). The experimenters wore odorless gloves during the whole experimental session.

Auditory stimuli White noise sounds of seven different durations $(208,272,336,400,464,528$, or $592 \mathrm{~ms})$ were presented via headphones (K511 AKG stereo headphones) at a 70-dB level.

\section{Procedure}

The experiment was run in a quiet and well-ventilated classroom setting, in groups ranging from five to eight blindfolded participants, and two experimenters sat on each side of each participant. White noise sounds were delivered through headphones and responses were given by pressing two keys of the keyboard ("Ctrl" and "Enter" keys). The response keys associated with the short and long duration were counterbalanced across participants. The temporal bisection task consisted of two phases: a training phase directly followed by a test phase. During the training phase, participants had to learn two anchor durations, a short one (208 ms) and a long one (592 ms). First, the participants had to listen to each duration, which were presented five times in alternation (following the procedure from Millot et al., 2016). Then the two anchor durations were 
randomly presented, ten times each, and participants had to categorize them as either short or long. During the test phase, participants had to categorize, in the same manner, 70 sounds of seven different durations: 208, 272, 336, 400, 464, 528 and $592 \mathrm{~ms}$ (each duration was thus presented ten times in random order overall). No feedback was given during the whole experiment. The participants were explicitly told that the experimenter would hold an object below their nose that might be odorized or not, and that they may or may not detect the odor because of inter-individual differences in olfactory sensitivity. During the test phase, the participants were presented with a single sniffin' stick filled either with strawberry odor (relaxing odor) or solvent only (blank control). While instructions were given, the experimenters presented the sniffin' sticks to the participants, which were then maintained until the end of the phase. Instructions were given orally to the participants and varied depending on the suggestion condition: the stimulus was described as being either relaxing or stimulating or not described in terms of activation properties (no-arousal suggestion condition). At the end of the temporal bisection task, participants were asked to complete a short questionnaire that considered potential variables that might have influenced the experiment (such as head cold, chronic allergies, etc.). The total duration of the experiment was $30 \mathrm{~min}$.

\section{Data analyses}

A seven-point psychometric function that related the target duration with the proportion of long responses was drawn for each participant of each experimental condition. A cumulative Gaussian sigmoidal function was fitted to the proportion of long responses through a maximum likelihood estimation procedure (Gagnon et al., 2018; Grondin et al., 2015). Two dependent variables were extracted from each function. One is the point of subjective equality (PSE). It is defined as the target duration corresponding to a predicted rate of long responses of $50 \%$, and is used as a measure of perceived duration: the smaller the PSE value, the longer the perceived duration.

The other dependent variable is the difference limen (DL). It is defined as the standard deviation parameter of the fitted cumulative Gaussian curve. This variable measures the participants' sensitivity to time: higher DL values denote poorer sensitivity.

\section{Results}

\section{Goodness of fit of psychometric functions}

The goodness of fit of psychometric functions was highly accurate in each olfactory condition. For the strawberry odor condition, the mean values of $\mathrm{R}^{2}$ in the no-arousal, relaxing, and stimulating groups were equal to $0.95,0.95$, and 0.94 , respectively. For the odorless blank condition, they were equal to $0.98,0.95$, and 0.95 , respectively.

\section{PSE analysis}

As illustrated in Fig. 1, a two-way analysis of variance (ANOVA) was conducted on PSE (considering "long" response proportions), with stimulus conditions (strawberry, odorless blank) and suggestion conditions (no-arousal, relaxing, stimulating) as between-subjects factors. This analysis showed a significant interaction between olfactory and suggestion conditions on PSE $(F(2,112)=5.92, p=.004$, partial $\left.\eta^{2}=.096\right)$, but neither a main effect of the olfactory condition $\left(F(1,112)=.05, p=.827\right.$, partial $\eta^{2}=.001$, nor of suggestion $\left(F(2,112)=.64, p=.529\right.$, partial $\left.\eta^{2}=.011\right)$ was significant.

Strawberry odor - no-arousal suggestion Planned comparisons showed that the PSE in the strawberry group was significantly higher than in the odorless blank group for the noarousal suggestion condition $F(1,112)=.229, p=.042,95 \%$ CI $[0.934,50.248]$ (see Table 1 and Fig. $1 \mathrm{a}$ and b). These results indicate that, without any suggestion about arousal properties, the strawberry odor led participants to underestimate durations compared to the odorless blank group, which is consistent with a relaxing effect of strawberry odor.

Strawberry odor - stimulating suggestion When strawberry was suggested to be stimulating, the PSE was significantly lower than without any suggestion (no-arousal condition), $F(1,112)=4.779, p=.031,95 \%$ CI $[2.651,53.979]$ (see Table 1 and Fig. 1c). These findings indicate that the relaxing effect of strawberry odor (i.e., based on the duration underestimation) seemed to fade away following the suggestion that this odor was stimulating.

In addition, the PSE in the stimulating suggestion group of the strawberry condition was not different from the odorless blank condition in the no-arousal suggestion group, $F(1,112)$ $=.044, p=.834,95 \% \mathrm{CI}[-22.940,28.388]$, further suggesting that the strawberry odor loses its relaxing effect when presented with a stimulating suggestion, without becoming stimulating either.

Strawberry odor - relaxing suggestion Suggesting that the strawberry odor was relaxing had no influence on the PSE, $F(1,112)<.001, p=.982,95 \%$ CI $[-25.013,25.582]$ (see Table 1 and Fig. 1c). In other words, the strawberry odor did not become more relaxing when suggested to be so. On the other hand, a relaxing suggestion did not influence the effect of the strawberry odor compared to an odorless blank, with the PSE being still significantly higher than that of the control group with no-arousal suggestion, $F(1,112)=3.929, p=$ $.049,95 \%$ CI [-50.603, -0.010$]$. 


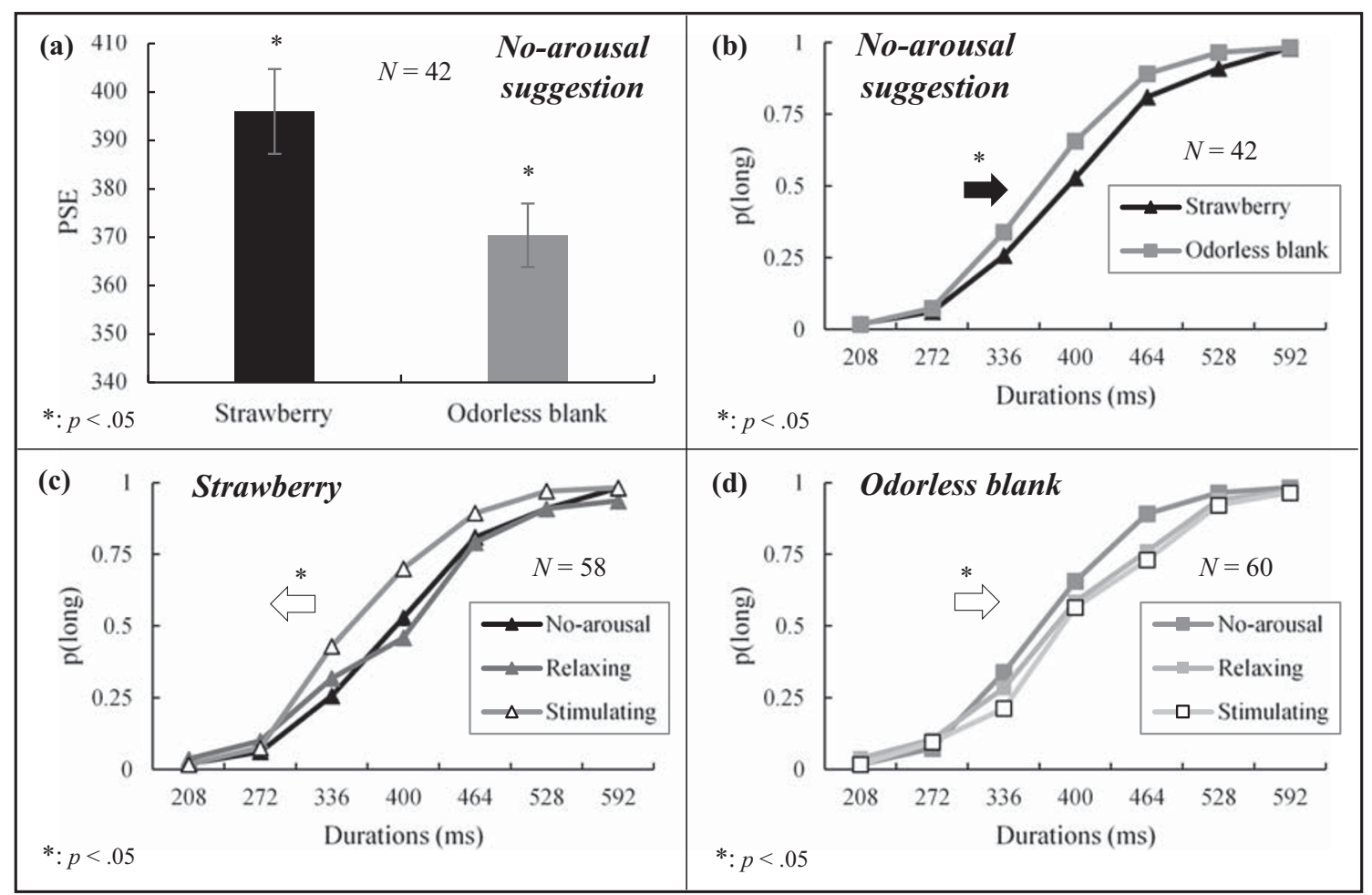

Fig. 1 Experiment 1. (Upper) Point of Subjective Equality (PSE; a) and mean proportion of "long" responses plotted as a function of time (b) for the olfactory conditions of the No-arousal suggestion groups. Error bars

indicate standard errors of mean. (Lower) Mean proportion of "long" responses plotted as a function of time in relation to prior suggestion with strawberry odor (c) and without odor (d)

Odorless blank condition With regards to the odorless blank condition (see Table 1 and Fig. 1d), the PSE in the no-arousal suggestion group was not significantly different from the relaxing one $(F(1,112)=2.458, p=.120,95 \%$ CI $[-45.313$, 5.281]), indicating that the suggestion of the eventual presence of a relaxing odor did not significantly impact the PSE. However, the PSE of the stimulating suggestion group was significantly higher than the no-arousal suggestion one, $F(1,112)=6.879, p=.010,95 \%$ CI $[-58.008,-8.081]$. Overall, this means that, in the odorless blank condition, the relaxing suggestion did not significantly affect time perception, whereas the stimulating suggestion led to an overestimation of duration.

\section{DL analysis}

In order to examine the potential effects of strawberry odor and suggestion on time sensitivity, another two-way ANOVA was conducted on DL considering olfactory conditions (i.e., strawberry, odorless blank) and suggestion (i.e., no-arousal, relaxing, stimulating) as between-subjects factors. This analysis showed no main effect of olfactory condition on DL $\left(F(1,112)=.01, p=.932\right.$, partial $\eta^{2}<.001$, no main effect of suggestion on DL $(F(2,112)=1.23, p=.297$, partial $\left.\eta^{2}=.021\right)$, and no significant interaction between olfactory and suggestion conditions $(F(2,112)=2.13, p=$ .124 , partial $\left.\eta^{2}=.037\right)$.

\section{Discussion}

The first goal of the present study was to determine if a relaxing odor such as strawberry could modulate time perception. The main results showed that, compared to the control group and in the absence of suggestion, participants exposed to the strawberry odor significantly underestimated sound durations (rightward horizontal shift of the sigmoidal-shaped function - higher PSE). This result is consistent with prior studies that show an underestimation of duration when participants are exposed to stimuli that are supposed to slow down the pacemaker's rate of pulse emission in the internal clock (Droit-Volet, Ramos, et al., 2013; Wearden, Philpott, \& Win, 1999).

Another goal of Experiment 1 was to examine whether participant expectancies (manipulated through prior verbal instructions) about the activation properties of the odor influenced temporal judgments and to determine if these expectancies can augment or reverse the effect of the odor itself. Our results showed no influence of the relaxing suggestion when participants were exposed to strawberry odor. This means that a congruent suggestion does not impact the initial relaxing effect of the strawberry odor. However, when this odor was previously described as being stimulating, its relaxing effect was negated. This impact of verbal suggestion confirms the results of the few previous studies that had already reported an influence of prior instructions 
in olfaction (Campenni et al., 2004; Dalton, 1996, 1999; Dalton et al., 1997; Howard \& Hughes, 2008). However, even though the strawberry odor lost its relaxing effect, it did not become stimulating, even after appropriate suggestion. These results preclude the hypothesis that the relaxing effects of odors could only be due to the participant's expectancy.

\section{Experiment 2}

In order to validate whether or not the underestimation of durations in the presence of a strawberry odor is due to more attention being paid to time in the presence of an olfactory stimulus, Experiment 2 was conducted using another odor (lemon), which is considered to be stimulating. Experiment 2 was also designed to determine whether the effects of expectancy found in Experiment 1 were specific to the strawberry odor or if they could be generalized by observing an opposite pattern with a supposed stimulating odor (i.e., lemon).

\section{Method}

\section{Participants}

One hundred and thirty-two female students from Burgundy University $\left(M_{\text {age }}=18.83 \pm 2.04\right.$ years $)$ were distributed into six independent groups in relation to olfactory condition (i.e., lemon odor, or odorless blank) and prior suggestion (i.e., noarousal, relaxing, stimulating suggestion): lemon-no-arousal suggestion $(N=21)$, lemon-relaxing $(N=21)$, or lemonstimulating $(N=22)$; and blank-no-arousal suggestion $(N=$ 25), blank-relaxing $(N=22)$, or blank-stimulating $(N=21)$ (see Table 2). All participants provided their consent prior to participation. The study was conducted in accordance with the Declaration of Helsinki. All participants self-reported normal olfactory sensitivity. None of these participants took part in Experiment 1.

Table 2 Experiment 2. Mean of Point of Subjective Equality (PSE) and standard deviation (SD) according to Olfactory (i.e., Lemon or Odorless Blank) and Suggestion (No-arousal, Relaxing, Stimulating) conditions

\begin{tabular}{lllllllll}
\hline & \multicolumn{3}{l}{ Lemon odor } & & & \multicolumn{2}{l}{ Odorless blank } \\
\cline { 2 - 4 } \cline { 7 - 8 } & N & PSE mean & SD & & N & PSE mean & SD \\
\hline No-arousal & 21 & $363.90^{*}$ & 39.35 & & 25 & 396.52 & 35.39 \\
Relaxing & 21 & 390.32 & 32.72 & & 22 & 379.82 & 34.57 \\
Stimulating & 22 & $378.41^{*}$ & 39.84 & & 21 & 377.50 & 35.41 \\
\hline
\end{tabular}

$* p<.05$ compared to odorless blank group in no-arousal suggestion condition

\section{Stimuli}

Olfactory stimuli A lemon odorant (essential oil "Nature et Découvertes ${ }^{\mathrm{TM}}$ "), $4 \mathrm{~mL}$ of a $10^{-2}$ solution, was loaded inside sniffin' sticks (Burghart ${ }^{\mathrm{TM}}$ ). In the same pretest as in Experiment 1, this stimulus was deemed the most stimulating among a pre-selection of 18 odors (see details of the test in the Online Supplementary Materials). Its perceived intensity and pleasantness were judged as equal to those of the strawberry odor used in Experiment 1. Blank sniffin' sticks contained only a solvent (mineral oil).

Auditory stimuli Auditory stimuli were exactly the same as in Experiment 1.

\section{Procedure}

The exact same experimental design as in Experiment 1 was used in Experiment 2 except that the odor presented was lemon and the odorless blank was mineral oil.

\section{Results}

\section{Goodness of fit of psychometric functions}

The goodness of fit of psychometric functions was highly accurate in each olfactory condition. For the lemon odor condition, the mean values of $\mathrm{R}^{2}$ in the no-arousal, relaxing, and stimulating groups were equal to $0.94,0.95$, and 0.96 , respectively. For the odorless blank condition, they were equal to $0.97,0.96$, and 0.97 , respectively.

\section{PSE analysis}

As illustrated in Fig. 2, a two-way ANOVA was conducted on PSE with olfactory condition (i.e., lemon, odorless blank) and suggestion (i.e., no-arousal, relaxing, stimulating) as between-subjects factors. This analysis showed no main effect of olfactory condition on PSE $(F(1,126)=$ $1.25, p=.266$, partial $\left.\eta^{2}=.001\right)$ and no main effect of instruction on PSE $\left(F(2,126)=0.43, p=.650\right.$, partial $\eta^{2}=$ .007). However, we observed a significant interaction between olfactory conditions and suggestion $(F(2,126)=$ $4.34, p=.015$, partial $\left.\eta^{2}=.064\right)$.

Lemon odor - no-arousal suggestion Planned comparisons revealed that PSE in the lemon group is significantly lower than in the odorless blank group in the no-arousal suggestion condition, $F(1,126)=9.223, p=.003,95 \%$ CI $[-53.882$, 11.365] (see Table 2 and Fig. 2a, b). These results indicate that, without suggestion about arousal properties, the lemon odor led participants to overestimate durations compared to 


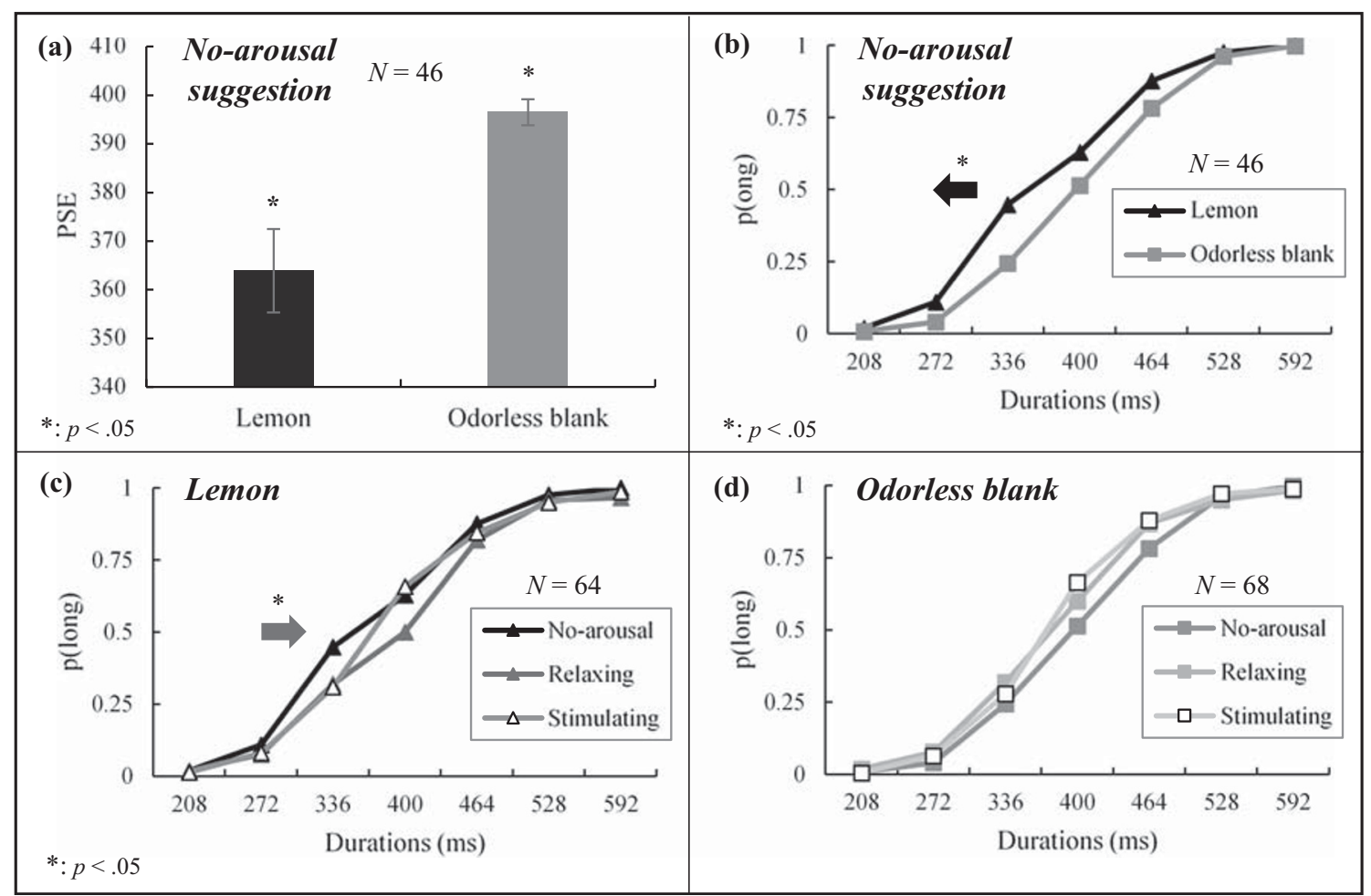

Fig. 2 Experiment 2. (Upper) Point of Subjective Equality (PSE; a) and mean proportion of "long" responses plotted as a function of time (b) for the olfactory conditions of the No-arousal suggestion groups. Error bars

participants in the odorless blank group, a finding that is consistent with a stimulating effect of lemon odor.

Lemon odor - relaxing suggestion When lemon was suggested to be relaxing, the PSE was significantly higher than when there was no suggestion, $F(1,126)=5.564, p=.020$, 95\% CI [-48.582, -4.255] (see Table 2 and Fig. 2c). This finding indicates that the stimulating effect of the lemon odor (i.e., based on overestimated durations) seems to fade following a suggestion that this odor was relaxing.

In addition, the PSE in the relaxing suggestion group of the lemon condition was not different from the odorless blank condition in the no-arousal suggestion group, $F(1,126)=$ $5.564, p=.020,95 \%$ CI [-48.582, -4.255], further suggesting that the lemon odor loses its stimulating effect after a relaxing suggestion, without becoming relaxing either.

Lemon odor - stimulating suggestion Suggesting that the lemon odor was stimulating had no influence on the PSE, $F(1,126)=1.718, p=.192,95 \%$ CI $[-36.421$, 7.399] (see Table 2 and Fig. 2c). In other words, the lemon odor did not become more stimulating when suggested to be so. On the other hand, the stimulating suggestion did not influence the effect of the lemon odor compared to the odorless blank, with the PSE being still significantly lower than that of the control group with no- indicate standard errors of mean. (Lower) Mean proportion of "long" responses plotted as a function of time in relation to prior suggestion with lemon odor (c) and without odor (d)

arousal suggestion, $F(1,126)=1.718, p=.192,95 \%$ CI $[-$ $36.421,7.400$ ] (see Table 2 and Fig. 2c).

Odorless blank condition With regards to the odorless blank condition (see Table 2 and Fig. 2d), the PSE in the no-arousal suggestion group was not significantly different from that of the participants in the relaxing or stimulating suggestion groups, respectively, $F(1,126)=2.478, p=.118,95 \%$ CI [$4.294,37.694], F(1,126)=3.135, p=.079,95 \%$ CI $[-2.237$, 40.279]. Overall, there was no influence of prior suggestion in the absence of odor.

\section{DL analysis}

Another two-way ANOVA was conducted on DL considering olfactory condition (i.e., lemon, odorless blank) and suggestion (i.e., no-arousal, relaxing, stimulating) as betweensubjects factors. This analysis showed no main effect of olfactory condition $\left(F(1,126)=2.09, p=.151\right.$, partial $\left.\eta^{2}=.016\right)$, but the main effect of suggestion is significant $(F(2,126)=$ $3.40, p=.037$, partial $\left.\eta^{2}=.051\right)$. The mean of the relaxing suggestion condition $(M=53.34 \pm 17.02)$ was significantly different from the mean of the no-arousal and stimulating conditions (respectively, $M=45.91 \pm 13.18$ and $M=45.91$ $\pm 15.46)$. The interaction between olfactory and suggestion 
conditions was not significant $(F(2,126)=0.03, p=.968$, partial $\left.\eta^{2}=.001\right)$.

\section{Discussion}

The main goal of Experiment 2 was first to determine if the presentation of a stimulating odor such as lemon would accelerate the pacemaker's rate of pulse emission in the internal clock in contrast with the relaxing odor used in Experiment 1 (i.e., strawberry). As expected, results showed that, in the absence of suggestion and compared to the control group, participants exposed to the lemon odor significantly overestimated sound durations (rightward horizontal shift of the sigmoidal-shaped function). This result is consistent with the numerous studies that reported an overestimation of time when participants are exposed to high-arousal stimuli (Boltz, 1994; Droit-Volet et al., 2011; Droit-Volet, Ramos, et al., 2013; Frederickx et al., 2013; Gil \& Droit-Volet, 2011; Noulhiane et al., 2007; Penton-Voak et al., 1996; Rattat, Matha, \& Cegarra, 2018; Wearden, Philpott, et al., 1999; Wearden, Williams, \& Jones, 2016, for a review, see Lake et al., 2016, and for an opinion article, see Droit-Volet \& Meck, 2007).

Another goal of Experiment 2 was to examine whether prior expectancy about the activation properties of the odor would influence temporal judgments in the lemon odor condition and, more precisely, if an incongruent suggestion can undo the effect of the odor as in Experiment 1. Our results showed no influence of the stimulating suggestion when participants are exposed to lemon odor. Like in Experiment 1, a congruent suggestion did not impact the initial effect of the odor, i.e., the stimulating effect of the lemon odor was not enhanced. However, when the lemon odor was priorly described as being relaxing, its stimulating effect was negated. The odor of lemon did not become relaxing either. This impact of expectancy corroborates the results of Experiment 1 .

\section{General discussion}

In the present study, we provide experimental evidence that pleasant odors can modulate the perception of time. Experiment 1 showed that participants exposed to a relaxing odor (strawberry) underestimated durations compared to participants exposed to a blank odorless control. Conversely, Experiment 2 showed that when exposed to a stimulating odor (lemon), participants overestimated durations. These findings are consistent with the numerous studies that report the distortion of time perception in other sensory modalities caused by arousal-based mechanisms (Droit-Volet et al., 2011; Droit-Volet, Ramos, et al., 2013; Frederickx et al., 2013; Gagnon et al., 2018; Gil \& Droit-Volet, 2011, 2012; Noulhiane et al., 2007; Rattat et al., 2018) rather than attentional-based ones (for a review, see Lake et al., 2016 and for an opinion article, see Droit-Volet \& Meck, 2007). Within the theoretical frame of the internal clock that contains a pacemaker-accumulator device, we can conclude that the strawberry odor decelerated the pacemaker's rate of pulse emission, whereas the lemon odor accelerated it.

As pointed out by Wearden, Philpott, et al. (1999), the slowing down of the pacemaker's activity (as shown in Experiment 1) is much less commonly observed than its speeding up. Only a few studies using the same experimental design demonstrated an increase as well as a decrease of the pacemaker's activity speed. In Wearden, Philpott, et al.'s (1999) study, the click trains technique was used in a temporal bisection task that consisted of learning standard durations preceded by clicks. This led participants to judge sounds in the context of a clock running fast, and to then categorize their durations, by contrast, with a relatively slowed down clock. As the authors expected, they found an underestimation of intermediate durations when the duration of the learned standards was preceded by clicks, interpreted as a "relative" slowing of the clock. In the same vein, in another study using emotional stimuli (Droit-Volet, Ramos, et al., 2013), participants had to categorize musical excerpts as being closer to the short or to the long anchor durations. A given excerpt was presented at different tempi since tempo is considered to be a main feature underlying the activation properties of music (Juslin \& Sloboda, 2013; Peretz, Gagnon, \& Bouchard, 1998; Vieillard et al., 2008). Findings showed that excerpts with a fast tempo were judged as being longer than excerpts with a slow one, suggesting a modification of the pacemaker's rate induced by tempo: slow tempo excerpts slow it down while fast tempo speeds it up. To summarize, the overall results of Experiments 1 and 2 pinpoint the ability of odors to implicitly induce a slower and a higher rate of the pacemaker of the internal clock, similar to other sensory modalities, using emotional and non-emotional stimuli, thereby testifying of their relaxing and stimulating effects.

Similarly, within the olfactory field, Schreuder et al. (2014) used a time production task with long durations (superior to $1 \mathrm{~h} 30 \mathrm{~min}$ ) and showed an arousal-based effect with a pleasant odor that is considered to be stimulating, namely rosemary. In this study, participants produced shorter durations when exposed to the stimulating odor compared to a control group without odor. However, the relaxing odor, namely peppermint, failed to demonstrate any relaxing effect. Notably, in Yue et al. (2016), participants produced longer durations (short sound intervals) when they were exposed to lavender odor (considered to be relaxing) compared to garlic and jasmine odor. One possible explanation for such results is that peppermint can also be implicitly considered as stimulating (Lemercier-Talbot et al., 2019). Moreover, Schreuder et al. did not interpret the effect of the rosemary odor on the basis of an arousal-based mechanism since no differences were observed in physiological measurements. One proposed interpretation 
could be that arousal-based mechanisms might be related to short durations rather than to long ones (Gros et al., 2015; Yue et al., 2016). However, it turns out that Millot et al. (2016) showed that when participants are exposed to a same unpleasant odor, sub-second durations involve an attentional-based mechanism (underestimation of sound durations) whereas the supra-second duration range involves an arousal-based mechanism (overestimation of sound durations). Their interpretations are congruent neither with the hypothesis of Gros et al. (2015) nor with our findings. However, it can be argued that negative and positive valences of odors could induce different temporal distortions, as observed in other sensory modalities, and, thus, should not be directly compared. In vision, for example, Angrilli, Cherubini, Pavese, and Manfredini (1997) found a crossover interaction between the valence and arousal properties of images (International Affective Picture System, IAPS; Lang, Bradley, \& Cuthbert, 1997): negative images were judged to be shorter than positive ones when both were characterized by low arousal, whereas the opposite pattern of results was observed (i.e., negative images were judged to be longer than positive ones) when images were characterized by high arousal. In the olfactory domain, Gros et al. (2015) reported an arousing effect of odors on a time reproduction task, regardless of their valence. However, the activation properties of the odorants used were not systematically controlled compared to similar studies in other sensory modalities (Angrilli et al., 1997; van Volkinburg \& Balsam, 2014). This conundrum points out the need for future research to select odorants according to their activation properties in addition to their valence properties. This will offer a more comprehensive explanation of the mechanisms that underlie the distortion of time induced by olfactory-elicited emotions. The present results clearly provide a demonstration of olfactory-based arousal changes for pleasant odors characterized by high and low arousal. Nevertheless, one might speculate on the recent idea that both attentional-based and arousal-based mechanisms could occur conjointly (Lake et al., 2016). This might depend on the interaction between the valence and activation properties of the presented odor as well as the range of durations used.

In our experimental setting, in the presence of the stimulus, participants were well aware of the odor and showed an altered performance in the temporal bisection task. However, as mentioned by Haviland-Jones, Wilson, and Freyberg (2016), even when odors are easily detected, it is unlikely that participants consciously use them as contextual cues, for example, to help a confederate, as in Baron's study (1997), or here, to categorize short and long sound durations. However, in order to prevent a potential explanation in terms of stimuluscaptured attention, further studies could benefit from the presentation of the stimuli at a subliminal level (without mentioning to the participant the presence of the stimulus). Moreover, from a more practical point of view, presentation techniques such as odorizing a room as in Brand, Thiabaud, and Dray (2016) or spraying the odorant inside the foam cover of a microphone as in Leleu et al. (2015) would be even more optimal and comfortable than holding a sniffing stick under the participant's nose for the entire experiment.

The second main goal of the present studies was to examine the influence of expectancy on the relaxing and stimulating effects of odors. Experiments 1 and 2 showed that congruent suggestions did not alter the relaxing effect of the strawberry odor nor the stimulating effect of the lemon odor. In contrast, when an incongruent suggestion was given (describing strawberry odor as stimulating and lemon as relaxing), the odors lost their effects on time perception, which was no longer different from that of the odorless blank group. This impact of expectancy on behavior is consistent with prior literature that shows an effect of subjective beliefs about perceived emotions triggered by odors (Dalton, 1996, 1999; Dalton et al., 1997) and by food and drink (Yeomans et al., 2008; Zellner et al., 2004). Indeed, this wellidentified phenomenon is so powerful that it can lead participants to report some discomfort from the "odor exposure" even when no odor is presented (Knasko, Gilbert, \& Sabini, 1990; O'Mahony, 1978). Observing the effects of expectancy gives credence to the idea that a psychological mechanism underlies the relaxing and stimulating effects of odors and thus may not (only) depend on an intrinsic pharmacological ability to affect the autonomic nervous system (Dalton, 1999; Herz, 2009; Johnson, 2011). As a matter of fact, these results are in line with the theories that consider information processing in humans as a combination of top-down and bottom-up processing (PiquerasFiszman \& Spence, 2015). Some authors consider that the affective responses to emotional stimuli are determined by expectancies as much as by the driving signals themselves (Affective Expectancy Model, AEM; Wilson, Lisle, Kraft, \& Wetzel, 1989; see Atlas \& Wager, 2013). The AEM describes two major effects of expectancy: assimilation and contrast. Assimilation occurs when the participant rearranges his/her judgment of a stimulus in order to reduce the discrepancy between his/her expectancy and his/her perception of the stimulus (to make both fit). Contrast occurs when the participant exaggerates the difference between his/her expectancy and the stimulus. According to the AEM, if the differences between the expectancy and the experience are slight, assimilation is more likely to be observed, whereas contrast may occur whenever the discrepancy is too large. The detection of the discrepancy between the stimulus' value and the affective expectancy requires fine-grained attention, depending on the degree of discrepancy, in order to truly evaluate the stimulus (Atlas \& Wager, 2013).

Our findings show that prior incongruent suggestions negate the a priori relaxing or stimulating properties of the odors but could not reverse them entirely (i.e., strawberry cannot become stimulating and lemon cannot become relaxing). These results differ from those of Campenni et al. (2004), because their relaxing odor (i.e., lavender) shifted from a 
relaxing effect (on physiological measures) to a stimulating effect when primed with a "stimulating" suggestion, whereas it was not the case here in Experiment 1 (with the strawberry odor). An explanation might consider the possibility of distinct effects of suggestion depending on the measures (physiological or behavioral). As previously suggested, it might be that behavioral and physiological measurements may reflect independent processes since they can be distinctively modulated (Diskin \& Hodgins, 2003; Gross, 1998; Papciak, Feuerstein, \& Spiegel, 1985; Sloan, Strauss, Quirk, \& Sajatovic, 1997, cited by Lake et al., 2016). Future research might use both behavioral and physiological measures in order to validate or refute this hypothesis within the field of olfactory-elicited emotions). However, according to the AEM, one might speculate that participants' expectancies were assimilated to the stimulus processing, suggesting that participants did not notice the discrepancy, or if so, the stimulus' value was not discrepant enough from their expectancies to lead to attentional capture. This is consistent with a recent study conducted in our lab (Baccarani et al., 2020), which showed that relaxing and stimulating properties are not necessarily perceived as opposites. This non-antagonist relationship between perceived relaxing and stimulating properties could explain an assimilation-like effect since some odors, depending on concentration, could also be considered, to a certain extent, both relaxing and stimulating.

Furthermore, one could argue that the effects of odors were not completely reversed because the effects of suggestion and of the odor itself could have been added to each other. However, congruent prior suggestion neither potentiated the relaxing effect of strawberry odor nor the stimulating effect of lemon odor. Thus, such an absence of amplification of the initial stimulus effect by congruent suggestion weakens an interpretation in terms of cumulative bottom-up and topdown effects. This pattern of results shares some similarities with the work of Yeomans et al. (2008) in which the positive expectancy of the participant did not magnify the pleasantness ratings of the food they were presented. In this study, participants assessed a highly novel food: smoked salmon icecream, which was presented either as an ice-cream, generating a fruity and sweet taste expectancy (discrepant expectancy), as a frozen savory cream (congruent expectancy), or was not described in a control condition. Pleasantness ratings did not differ between the control group and the congruent expectancy group (savory cream label).

It is well established that odors are strongly and easily associated with specific emotions (Herz, 2002, 2005; Herz, Schankler, \& Beland, 2004), often since the very beginning of life (Mennella \& Beauchamp, 1991, 1993, 1996; Mennella, Johnson, \& Beauchamp, 1995; Schaal, Soussignan, \& Marlier, 2002). These long-term learned associations automatically trigger experience-dependent expectancies in the presence of the stimulus (Atlas \& Wager, 2013) and might compete with the newly learned associations evoked by incongruent verbal suggestions. In olfaction, the potency of long-term representation has mostly been shown in the hedonic dimension (Herz, 2002). They are directly linked to one's individual personal history, expertise, or culture. For instance, in a study conducted in the UK in the 1960s, the smell of wintergreen (methyl salicylate) was judged unpleasant (Moncrieff, 1966), whereas Americans considered it a very pleasant odor (Cain \& Johnson, 1978). The explanation is to be found in cultural history. At that time, wintergreen was associated with a rub-on analgesic widely used in the UK during World War II, whereas it was associated with a candy "mint" smell in the USA (Herz, 2002). Although they have never been experimentally investigated yet, the long-term representations associated with the relaxing and stimulating properties of odors might work in a similar way. One recent work (Lemercier-Talbot et al., 2019) documents this idea by showing an automatic and unconscious attribution of stimulating properties to peppermint odor and relaxing properties to vanilla odor. Thus, one possible explanation of our results might be that suggestions have only a limited impact and cannot completely rule out a lifetime of learned associations. This means that even if participants are told so, the odor of strawberry cannot become stimulating nor can that of lemon become relaxing. However, this explanation might still be too speculative at this early stage since, as mentioned above, recent work suggests that some odors (e.g., strawberry or lavender) can be judged both relaxing and stimulating depending on the odorant and concentration used (Baccarani et al., 2020).

Furthermore, psychosocial factors may also be involved since it has been recently shown that differences in personality could predict usage and perceived effectiveness of essential oils (Ackerman \& Chopik, 2020). Thus, personality factors could explain (at least partly) how participants respond to verbal congruent or incongruent suggestions in relation to odors. In that respect, investigating the role of culture, context, or individual experience and expertise represents new avenues of research toward the better understanding of the nature and role of the unconscious mental representations associated with the relaxing and stimulating properties of olfactory stimuli.

Our data confirm and extend upon prior findings about the role played by the participant's expectancy in emotional responses to odors but refute the hypothesis that olfactory-based relaxing and stimulating effects are only due to this factor (at least via the manipulation of verbal instructions).

Additionally, and rather unexpectedly, the results of Experiment 1 showed an influence of the stimulating suggestion on participants of the blank odorless groups; their PSE was significantly higher with the stimulating suggestion than with the no-arousal suggestion. In Experiment 2, we also found a main effect of suggestion on DL. To our knowledge, the influence of expectancy on the internal clock in the absence of an external stimulus (of any sensory modality) has not yet been documented. These results are inconsistent with an arousalbased mechanism involving a decrease of the pacemaker's rate 
of pulse emission. They might rather be interpreted as originating from an attentional-based mechanism, with participants being less focused on the task because of peculiar instructions, as also suggested by their decreased time sensitivity (i.e., their significantly larger DL). Our design required control groups in which participants were explicitly told of the presence of a stimulus while they could realize that it was obviously absent. These results are congruent with a contrast effect described by the AEM, according to which the detection of the discrepancy between the stimulus value and the affective expectancy (disconfirmation of expectations) leads to an attentional cost, forcing the subject to pay attention to the stimulus (Atlas \& Wager, 2013). The difference between participants of Experiment 1 and Experiment 2 in blank groups remains hard to understand and future research should investigate these questions in greater depth, especially in the light of the AEM.

\section{Conclusion}

To conclude, Experiments 1 and 2 promote the use of the temporal bisection task as a well-suited experimental tool when investigating the emotional effects of odors and should be considered among other more popular implicit behavioral tasks (e.g., affective priming, IAT, etc.; De Houwer \& Moors, 2010). Our results especially encourage its use as an implicit measure of the relaxing and stimulating effects of odors since it specifically enables revealing arousal-based mechanisms. Moreover, the relaxing effect of the strawberry odor and the stimulating effect of the lemon odor can be negated only when a prior verbal suggestion carries an incongruent message. Regarding the potential explanatory mechanisms involved, our study confirms that the relaxing and stimulating effects of odors are underpinned by the slowing down or the increase of the speed of the internal clock, which could be partly modulated by the participant's expectancy.

Acknowledgements This work was supported by a $\mathrm{PhD}$ Scholarship from the French Ministry of Research awarded to A. B. The Natural Sciences and Engineering Research Council of Canada and the Social Sciences and Humanities Research Council of Canada have also financially supported this research. The authors would like to thank Monique Smeets and Fabrice Damon for their constructive comments on earlier versions of the manuscript, and Jamie McArthur for her careful revision of the manuscript. The authors are also grateful to Ana Milojevic and Shona Duval for technical support.

\section{References}

Ackerman, L. S., \& Chopik, W. J. (2020). Individual differences in personality predict the use and perceived effectiveness of essential oils. PLoS ONE, 15(3), e0229779. https://doi.org/10.1371/journal.pone. 0229779
Angrilli, A., Cherubini, P., Pavese, A., \& Manfredini, S. (1997). The influence of affective factors on time perception. Perception and Psychophysics, 59(6), 972-982. https://doi.org/10.3758/ BF03205512

Atlas, L. Y., \& Wager, T. (2013). Expectancies and beliefs: Insights from cognitive neuroscience. In The Oxford Handbook of Cognitive Neuroscience, Volume 2: The Cutting Edges (Vol. 2, pp. 359381). Oxford University Press. https://doi.org/10.1093/oxfordhb/ 9780199988709.013.0023

Baccarani, A., Brand, G., Dacremont, C., Valentin, D., \& Brochard, R. (2020). The influence of stimulus concentration and odor intensity on relaxing and stimulating perceived properties of odors. Food Quality and Preference, 87, 104030. https://doi.org/10.1016/j. foodqual.2020.104030

Baron, R. A. (1997). The sweet smell of... helping: Effects of pleasant ambient fragrance on prosocial behavior in shopping malls. Personality and Social Psychology Bulletin, 23(5), 498-503. https://doi.org/10.1177/0146167297235005

Bensafi, M., Rouby, C., Farget, V., Bertrand, B., Vigouroux, M., \& Holley, A. (2002). Autonomic nervous system responses to odours: The role of pleasantness and arousal. Chemical Senses, 27(8), 703709. https://doi.org/10.1093/chemse/27.8.703

Boltz, M. G. (1994). Changes in internal tempo and effects on the learning and remembering of event durations. Journal of Experimental Psychology: Learning, Memory, and Cognition, 20(5), 1154-1171. https://doi.org/10.1037/0278-7393.20.5.1154

Brand, G., Thiabaud, F., \& Dray, N. (2016). Influence of ambient odors on time perception in a retrospective paradigm. Perceptual and Motor Skills, 122(3), 799-811. https://doi.org/10.1177/ 0031512516647716

Cain, W. S., \& Johnson, F. (1978). Lability of odor pleasantness: Influence of mere exposure. Perception, 7(4), 459-465. https://doi. org/10.1068/p070459

Campenni, C. E., Crawley, E. J., \& Meier, M. E. (2004). Role of suggestion in odor-induced mood change. Psychological Reports, 94, 1127-1136. https://doi.org/10.2466/pr0.94.3c.1127-1136

Chrea, C., Grandjean, D., Delplanque, S., Cayeux, I., Le Calvé, B., Aymard, L., ... Scherer, K. R. (2009). Mapping the semantic space for the subjective experience of emotional responses to odors. Chemical Senses, 34(1), 49-62. https://doi.org/10.1093/chemse/ bjn052

Dalton, P. (1996). Odor perception and beliefs about risk. Chemical Senses, 21(4), 447-458. https://doi.org/10.1093/chemse/21.4.447

Dalton, P. (1999). Cognitive influences on health symptoms from acute chemical exposure. Health Psychology, 18, 579-590.

Dalton, P. (2000). Psychophysical and behavioral characteristics of olfactory adaptation. Chemical Senses, 25(4), 487-492. https://doi.org/ 10.1093/chemse/25.4.487

Dalton, P., Wysocki, C. J., Brody, M. J., \& Lawley, H. J. (1997). The influence of cognitive bias on the perceived odor, irritation and health symptoms from chemical exposure. International Archives of Occupational and Environmental Health, 69, 407-417. https:// doi.org/10.1007/s004200050168

De Houwer, J., \& Moors, A. (2010). Implicit measures: Similarities and differences. In B. Gawronski \& B. K. Payne (Eds.), Handbook of implicit social cognition: Measurement, theory, and applications (pp. 176-193). Guilford Publications.

Delplanque, S., Chrea, C., Grandjean, D., Ferdenzi, C., Cayeux, I., Porcherot, C., ... Scherer, K. R. (2012). How to map the affective semantic space of scents. Cognition and Emotion, 26(5), 885-898. https://doi.org/10.1080/02699931.2011.628301

Diego, M. A., Jones, N. A., Field, T., Hernandez-Reif, M., Schanberg, S., Kuhn, C., ... Galamaga, M. (1998). Aromatherapy positively affects mood, EEG patterns of alertness and math computations. International Journal of Neuroscience, 96(3-4), 217-224. https:// doi.org/10.3109/00207459808986469 
Diskin, K. M., \& Hodgins, D. C. (2003). Psychophysiological and subjective arousal during gambling in pathological and nonpathological video lottery gamblers. International Gambling Studies, 3(1), 37-51. https://doi.org/10.1080/14459790304590

Droit-Volet, S., Fayolle, S., Lamotte, M., \& Gil, S. (2013). Time, emotion and the embodiment of timing. Timing and Time Perception, 1, 99126. https://doi.org/10.1163/22134468-00002004

Droit-Volet, S., Fayolle, S. L., \& Gil, S. (2011). Emotion and time perception: Effects of film-induced mood. Frontiers in Integrative Neuroscience, 5, 251-252. https://doi.org/10.3389/fnint.2011. 00033

Droit-Volet, S., \& Gil, S. (2009). The time-emotion paradox. Philosophical Transactions of the Royal Society B: Biological Sciences, 364(1525), 1943-1953. https://doi.org/10.1098/rstb. 2009.0013

Droit-Volet, S., \& Meck, W. H. (2007). How emotions colour our perception of time. Trends in Cognitive Sciences, 11(12), 504-513. https://doi.org/10.1016/j.tics.2007.09.008

Droit-Volet, S., Meck, W. H., \& Penney, T. B. (2007). Sensory modality and time perception in children and adults. Behavioural Processes, 74(2), 244-250. https://doi.org/10.1016/j.beproc.2006.09.012

Droit-Volet, S., Ramos, D., Bueno, J. L. O., \& Bigand, E. (2013). Music, emotion, and time perception: The influence of subjective emotional valence and arousal? Frontiers in Psychology, 4(417), 1-12. https:// doi.org/10.3389/fpsyg.2013.00417

Ferdenzi, C., Delplanque, S., Barbosa, P., Court, K., Guinard, J.-X., Guo, T., ... Grandjean, D. (2013). Affective semantic space of scents. Towards a universal scale to measure self-reported odor- related. Food Quality and Preference, 30, 128-138.

Frederickx, S., Verduyn, P., Koval, P., Brans, K., Brunner, B., Laet, I. De, ... Hofmans, J. (2013). The relationship between arousal and the remembered duration of positive events. Applied Cognitive Psychology, 27(4), 493-496. https://doi.org/10.1002/acp.2926

Gagnon, C., Bégin, C., Laflamme, V., \& Grondin, S. (2018). Temporal processing of joyful and disgusting food pictures by women with an eating disorder. Frontiers in Human Neuroscience, 12(April), 1-23. https://doi.org/10.3389/fnhum.2018.00129

Gamache, P., Grondin, S., \& Zakay, D. (2011). Multidisciplinary aspects of time and time perception. In A. Vatakis, A. Esposito, M. Giagkou, F. Cummins, \& G. Papadelis (Eds.), Multidisciplinary aspects of time and time perception (pp. 137-150). Verlag, Berlin, Heidelberg: Springer. https://doi.org/10.1007/978-3-642-21478-3

Gibbon, J., Church, R. M., \& Meck, W. H. (1984). Scalar timing in memory. Annals of the New York Academy of Sciences, 423(1), 52-77. https://doi.org/10.1111/j.1749-6632.1984.tb23417.x

Gil, S., \& Droit-Volet, S. (2011). "Time flies in the presence of angry faces"... depending on the temporal task used! Acta Psychologica, 136(3), 354-362. https://doi.org/10.1016/j.actpsy.2010.12.010

Gil, S., \& Droit-Volet, S. (2012). Emotional time distortions: The fundamental role of arousal. Cognition and Emotion, 26(5), 847-862. https://doi.org/10.1080/02699931.2011.625401

Grabenhorst, F., Rolls, E. T., \& Bilderbeck, A. (2008). How cognition modulates affective responses to taste and flavor: Top-down influences on the orbitofrontal and pregenual cingulate cortices. Cerebral Cortex, 18(7), 1549-1559. https://doi.org/10.1093/cercor/bhm185

Grommet, E. K., Droit-Volet, S., Gil, S., Hemmes, N. S., Baker, A. H., \& Brown, B. L. (2011). Time estimation of fear cues in human observers. Behavioural Processes, 86, 88-93. https://doi.org/10.1016/ j.beproc. 2010.10.003

Grondin, S. (2008). Psychology of time. (S. Grondin, Ed.) (3rd ed.). Emerald Group Publishing.

Grondin, S. (2010). Timing and time perception: A review of recent behavioral and neuroscience findings and theoretical directions. Attention, Perception, and Psychophysics, 72(3), 561-582. https:// doi.org/10.3758/APP.72.3.561
Grondin, S. (2020). The perception of time: Your questions answered. New York: Routledge.

Grondin, S., Laflamme, V., Bienvenue, P., Labonté, K., \& Roy, M. L. (2015). Sex effect in the temporal perception of faces expressing anger and shame. International Journal of Comparative Psychology, 28(2006), 1-11.

Grondin, S., Laflamme, V., \& Gontier, É. (2014). Effect on perceived duration and sensitivity to time when observing disgusted faces and disgusting mutilation pictures. Attention, Perception, and Psychophysics, 76(6), 1522-1534. https://doi.org/10.3758/s13414014-0682-7

Gros, A., Giroud, M., Bejot, Y., Rouaud, O., Guillemin, S., Eboulé, C. A., ... Martin, M. L. (2015). A time estimation task as a possible measure of emotions: Difference depending on the nature of the stimulus used. Frontiers in Behavioral Neuroscience, 9(143). https://doi.org/ 10.3389/fnbeh. 2015.00143

Gross, J. J. (1998). Antecedent- and response-focused emotion regulation: Divergent consequences for experience, expression, and physiology. Journal of Personality and Social Psychology, 74(1), 224237. https://doi.org/10.1037/0022-3514.74.1.224

Guéguen, N., \& Petr, C. (2006). Odors and consumer behavior in a restaurant. International Journal of Hospitality Management, 25(2), 335-339. https://doi.org/10.1016/j.ijhm.2005.04.007

Haviland-Jones, J., Wilson, P., \& Freyberg, R. (2016). Olfaction: Explicit and implicit emotional processing. In L. Feldman Barrett, M. Lewis, \& J. M. Haviland-Jones (Eds.), Handbook of Emotions (pp. 199214). New York: Guildford Press.

Herz, R. S. (2002). Influences of odors on mood and affective cognition. In C. Rouby, B. Schaal, D. Dubois, R. Gervais, \& A. Holley (Eds.), Olfaction, Taste and Cognition (pp. 160-177). Cambridge: Cambridge Publications.

Herz, R. S. (2005). Odor-associative learning and emotion: Effects on perception and behavior. Chemical Senses, 30, 250-251. https:// doi.org/10.1093/chemse/bjh209

Herz, R. S. (2009). Aromatherapy facts and fictions: A scientific analysis of olfactory effects on mood, physiology and behavior. International Journal of Neuroscience, 119(2), 263-290. https:// doi.org/10.1080/00207450802333953

Herz, R. S., Schankler, C., \& Beland, S. (2004). Olfaction, emotion and associative learning: Effects on motivated behavior. Motivation and Emotion, 28(4), 363-383. https://doi.org/10.1007/s11031-004$2389-\mathrm{x}$

Hongratanaworakit, T. (2004). Physiological effects in aromatherapy. Songklanakarin Journal of Science and Technology, 26(1), 117 125.

Howard, S., \& Hughes, B. M. (2008). Expectancies, not aroma, explain impact of lavender aromatherapy on psychophysiological indices of relaxation in young healthy women. British Journal of Health Psychology, 13(4), 603-617. https://doi.org/10.1348/ $135910707 \mathrm{X} 238734$

Jakubowski, K., Halpern, A. R., Grierson, M., \& Stewart, L. (2015). The effect of exercise-induced arousal on chosen tempi for familiar melodies. Psychonomic Bulletin and Review, 22(2), 559-565. https:// doi.org/10.3758/s13423-014-0687-1

Johnson, A. J. (2011). Cognitive facilitation following intentional odor exposure. Sensors, 11(5), 5469-5488. https://doi.org/10.3390/ s110505469

Juslin, P. N., \& Sloboda, J. A. (2013). Music and emotion. In D. Deutsch (Ed.), The Psychology of Music (3rd ed., pp. 583-645). Amsterdam: Elsevier. https://doi.org/10.1016/B978-0-12-381460-9.00015-8

Kiecolt-Glaser, J. K., Graham, J. E., Malarkey, W. B., Porter, K., Lemeshow, S., \& Glaser, R. (2008). Olfactory influences on mood and autonomic, endocrine, and immune function. Psychoneuroendocrinology, 33(3), 328-339. https://doi.org/10. 1016/j.psyneuen.2007.11.015 
Kikuchi, A., Yamaguchi, H., Tanida, M., Abe, T., \& Uenoyama, S. (1992). Effects of odors on cardiac response patterns and subjective states in a reaction time task. Tohoku Psychologica Folia, 52, 74 82.

Knasko, S. C., Gilbert, A. N., \& Sabini, J. (1990). Emotional state, physical well-Being, and performance in the presence of feigned ambient odor. Journal of Applied Social Psychology, 20(16), 1345-1357. https://doi.org/10.1111/j.1559-1816.1990.tb01476.x

Kopec, C. D., \& Brody, C. D. (2010). Human performance on the temporal bisection task. Brain and Cognition, 74(3), 262-272. https:// doi.org/10.1016/j.bandc.2010.08.006

Lake, J. I., LaBar, K. S., \& Meck, W. H. (2016). Emotional modulation of interval timing and time perception. Neuroscience and Biobehavioral Reviews, 64, 403-420. https://doi.org/10.1016/j. neubiorev.2016.03.003

Lang, P. J., Bradley, M. M., \& Cuthbert, B. N. (1997). International affective picture system (IAPS): Technical manual and affective ratings. NIMH Center for the Study of Emotion and Attention, 1, $39-58$.

Lejeune, H. (2000). Prospective timing, attention and the switch A response to 'Gating or switching? gating is a better model of prospective timing' by Zakay. Behavioural Processes, 52(2-3), 71-76. https://doi.org/10.1016/S0376-6357(00)00136-4

Leleu, A., Demily, C., Franck, N., Durand, K., Schaal, B., \& Baudouin, J.-Y. (2015). The odor context facilitates the perception of lowintensity facial expressions of emotion. PLoS ONE, 10(9), e0138656. https://doi.org/10.1371/journal.pone.0138656

Lemercier-Talbot, A., Coppin, G., Cereghetti, D., Porcherot, C., Cayeux, I., \& Delplanque, S. (2019). Measuring automatic associations between relaxing/energizing feelings and odors. Food Quality and Preference, 77, 21-31. https://doi.org/10.1016/j.foodqual.2019.04. 010

Martin, G. N. (1998). Human electroencephalographic (EEG) response to olfactory stimulation: Two experiments using the aroma of food. International Journal of Psychophysiology, 30(3), 287-302. https://doi.org/10.1016/S0167-8760(98)00025-7

Mennella, J. A., \& Beauchamp, G. K. (1991). The transfer of alcohol to human milk: Effects on flavor and infants and the infant's behavior. New England Journal of Medicine, 325(14), 981-985. https://doi. org/10.1056/NEJM199309303291401

Mennella, J. A., \& Beauchamp, G. K. (1993). The effects of repeated exposure to garlic-flavored milk on the nursling's behavior. Pediatric Research, 34(6), 805-808. https://doi.org/10.1203/ 00006450-199312000-00022

Mennella, J. A., \& Beauchamp, G. K. (1996). The human infants' response to vanilla flavors in mother's milk and formula. Infant Behavior and Development, 19(1), 13-19. https://doi.org/10.1016/ S0163-6383(96)90040-5

Mennella, J. A., Johnson, A., \& Beauchamp, G. K. (1995). Garlic ingestion by pregnant women alters the odor of amniotic fluid. Chemical Senses, 20(2), 207-209. https://doi.org/10.1093/chemse/20.2.207

Millot, J.-L., Laurent, L., \& Casini, L. (2016). The influence of odors on time perception. Frontiers in Psychology, 7(181), 1-9. https://doi. org/10.3389/fpsyg.2016.00181

Mioni, G., Laflamme, V., Grassi, M., \& Grondin, S. (2018). The effect of emotional spoken words on time perception depends on the gender of the speaker. Timing and Time Perception, 6(1), 1-13. https://doi. org/10.1163/22134468-00002096

Miró, E., Cano, M. C., Espinosa-Fernández, L., \& Buela-Casal, G. (2003). Time estimation during prolonged sleep deprivation and its relation to activation measures. Human Factors, 45(1), 148159. https://doi.org/10.1518/hfes.45.1.148.27227

Moncrieff, R. W. (1966). Odour preferences. New York: Wiley. https:// doi.org/10.2307/3150362
Noulhiane, M., Mella, N., Samson, S., Ragot, R., \& Pouthas, V. (2007). How emotional auditory stimuli modulate time perception. Emotion, 7(4), 697-704. https://doi.org/10.1037/1528-3542.7.4.697

O’Mahony, M. (1978). Smell illusions and suggestion: Reports of smells contingent on tones played on television and radio. Chemical Senses and Flavour, 3(2), 183-189. https://doi.org/10.1093/chemse/3.2. 183

Papciak, A. S., Feuerstein, M., \& Spiegel, J. A. (1985). Stress reactivity in alexithymia: Decoupling of physiological and cognitive responses. Journal of Human Stress, 11(3), 135-142. https://doi.org/10.1080/ 0097840X.1985.9936750

Penton-Voak, I. S., Edwards, H., Percival, A., \& Wearden, J. H. (1996). Speeding up an internal clock in humans? Effects of click trains on subjective duration. Journal of Experimental Psychology: Animal Behavior Processes, 22(3), 307-320. https://doi.org/10.1037/00977403.22.3.307

Peretz, I., Gagnon, L., \& Bouchard, B. (1998). Music and emotion: Perceptual determinants, immediacy, and isolation after brain damage. Cognition, 68(2), 111-141. https://doi.org/10.1016/S00100277(98)00043-2

Piqueras-Fiszman, B., \& Spence, C. (2015). Sensory expectations based on product-extrinsic food cues: An interdisciplinary review of the empirical evidence and theoretical accounts. Food Quality and Preference, 40(PA), 165-179. https://doi.org/10.1016/j.foodqual. 2014.09.013

Porcherot, C., Delplanque, S., Raviot-Derrien, S., Calvé, B. Le, Chrea, C., Gaudreau, N., \& Cayeux, I. (2010). How do you feel when you smell this? Optimization of a verbal measurement of odor-elicited emotions. Food Quality and Preference, 21(8), 938-947. https://doi. org/10.1016/j.foodqual.2010.03.012

Rattat, A. C., Matha, P., \& Cegarra, J. (2018). Time flies faster under time pressure. Acta Psychologica, 185, 81-86. https://doi.org/10.1016/j. actpsy.2018.01.014

Sayorwan, W., Siripornpanich, V., Piriyapunyaporn, T., Hongratanaworakit, T., Kotchabhakdi, N., \& Ruangrungsi, N. (2012). The effects of lavender oil inhalation on emotional states, autonomic nervous system, and brain electrical activity. Journal of the Medical Association of Thailand, 95(4), 598-606.

Sayowan, W., Siripornpanich, V., Hongratanaworakit, T., Kotchabhakdi, N., \& Ruangrungsi, N. (2013). The effects of jasmine oil inhalation on brain wave activies and emotions. Journal of Health Research, 27(2).

Schaal, B., Soussignan, R., \& Marlier, L. (2002). Olfactory cognition at the start of life: The perinatal shaping of selective odor responsiveness. In C. Rouby, B. Schaal, D. Dubois, R. Gervais, \& A. Holley (Eds.), Olfaction, Taste and Cognition (pp. 421-440). United Kingdom: Cambridge Publications. https://doi.org/10.1093/brain/ awg287

Schirmer, A. (2016). Editorial of the special issue on emotion and time Time perception: In the heat of the moment. Timing and Time Perception, 4(1), 1-6. https://doi.org/10.1163/22134468-00002062

Schreuder, E., Hoeksma, M. R., Smeets, M. A. M. M., \& Semin, G. R. (2014). The effects of odor and body posture on perceived duration. Frontiers in Neurorobotics, 8, 6. https://doi.org/10.3389/fnbot. 2014.00006

Sloan, D. M., Strauss, M. E., Quirk, S. W., \& Sajatovic, M. (1997). Subjective and expressive emotional responses in depression. Journal of Affective Disorders, 46(2), 135-141. https://doi.org/10. 1016/S0165-0327(97)00097-9

Treisman, M. (1963). Temporal discrimination and the indifference interval. Implications for a model of the "internal clock". Psychological Monographs, 77(13), 1-31. https://doi.org/10.1037/h0093864

Vallet, W., Laflamme, V., \& Grondin, S. (2019). An EEG investigation of the mechanisms involved in the perception of time when expecting emotional stimuli. Biological Psychology, 148, 107777. https://doi.org/10.1016/j.biopsycho.2019.107777 
van Volkinburg, H., \& Balsam, P. (2014). Effects of emotional valence and arousal on time perception. Timing \& Time Perception, 2(3), 360-378. https://doi.org/10.1163/22134468-00002034

Vieillard, S., Peretz, I., Gosselin, N., Khalfa, S., Gagnon, L., \& Bouchard, B. (2008). Happy, sad, scary and peaceful musical excerpts for research on emotions. Cognition and Emotion, 22(4), 720-752. https://doi.org/10.1080/02699930701503567

Voyer, D., \& Reuangrith, E. (2015). Perceptual asymmetries in a time estimation task with emotional sounds. Laterality, 20(2), 211-231. https://doi.org/10.1080/1357650X.2014.953956

Wearden, J. H., Philpott, K., \& Win, T. (1999). Speeding up and (...relatively...) slowing down an internal clock in humans. Behavioural Processes. https://doi.org/10.1016/S0376-6357(99)00004-2

Wearden, J. H., Pilkington, R., \& Carter, E. (1999). "Subjective lengthening" during repeated testing of a simple temporal discrimination. Behavioural Processes, 46(1), 25-38. https://doi.org/10.1016/ S0376-6357(98)00059-X

Wearden, J. H., Williams, E. A., \& Jones, L. A. (2016). What speeds up the internal clock? Effects of clicks and flicker on duration judgements and reaction time. Quarterly Journal of Experimental Psychology, 70(3), 488-503. https://doi.org/10.1080/17470218. 2015.1135971

Williams, E. A., Solodow, E., Henderson, J. L., Stewart, A. J., \& Jones, L. A. (2020). Do click trains dilate time perception due to physiological arousal ? https://doi.org/10.31234/OSF.IO/78W43

Wilson, T. D., Lisle, D. J., Kraft, D., \& Wetzel, C. G. (1989). Preferences as expectation-driven inferences: Effects of affective expectations on affective experience. Journal of Personality and Social
Psychology, 56(4), 519-530. https://doi.org/10.1037/0022-3514. 56.4.519

Yeomans, M. R., Chambers, L., Blumenthal, H., \& Blake, A. (2008). The role of expectancy in sensory and hedonic evaluation: The case of smoked salmon ice-cream. Food Quality and Preference, 19(6), 565-573. https://doi.org/10.1016/j.foodqual.2008.02.009

Yue, Z., Gao, T., Chen, L., \& Wu, J. (2016). Odors bias time perception in visual and auditory modalities. Frontiers in Psychology, 7(535). https://doi.org/10.3389/fpsyg.2016.00535

Zellner, D. A., Strickhouser, D., \& Tornow, C. E. (2004). Disconfirmed hedonic expectations produce perceptual contrast, not assimilation. American Journal of Psychology, 117(3), 363-387. https://doi.org/ $10.2307 / 4149006$

Zhou, B., Feng, G., Chen, W., \& Zhou, W. (2018). Olfaction warps visual time perception. Cerebral Cortex, 28(5), 1718-1728. https://doi. org/10.1093/cercor/bhx068

Open Practices Statement Neither of the experiments reported in this article was formally preregistered. The data have been made available on OSF at: https://osf.io/t2jwx/?view_only=ea16165ab50d4b08a84138dc3d13822c.

Publisher's note Springer Nature remains neutral with regard to jurisdictional claims in published maps and institutional affiliations. 